\title{
Las bases económicas de una entidad política maya. El caso de Toniná
}

\section{The Economic Basis of a Maya Political Entity. The Case of Toniná}

\author{
ERIC TALADOIRE \\ Unité Mixte de Recherche Archéologie des Amériques, \\ Université Paris 1 Panthéon-Sorbonne
}

\begin{abstract}
Resumen: La entidad política de Toniná, por su ubicación marginal en un valle abundante en recursos naturales, ocupaba un lugar especial entre las ciudades mayas. A pesar de la riqueza natural del valle de Ocosingo, Toniná carece de un acceso fácil a varios bienes de prestigio, lo que influyó probablemente sobre su actitud bélica en contra de ciudades rivales y su búsqueda de esos productos indispensables para la dinastía local.
\end{abstract}

Palabras clave: Toniná, recursos naturales, economía política, intercambio.

\begin{abstract}
Because its marginal location, in a valley rich in natural resources, the Toniná polity had a special place among Maya cities. In spite of the abundant natural resources of the Ocosingo valley, Toniná lacks easy access to several luxury products, which might have influenced its bellicose attitude towards many rival entities, and its search of the prestigious resources needed by the local dynasty.
\end{abstract}

KEYwORDs: Toniná, natural resources, political economy, exchange.

RECEPCIÓN: 5 de febrero de 2015.

ACEPTACIÓN: 7 de septiembre de 2015.

DOI: 10.19130/iifl.ecm.2016.48.753

\section{Introducción}

Existe un gran número de trabajos de diversa índole y de excelente calidad sobre los recursos naturales, su explotación y las actividades económicas de las ciudades mayas (ver por ejemplo Masson y Freidel, 2002; Forné et al., 2014). Varios autores se han interesado en los recursos geológicos, florísticos, faunísticos y en su análisis detallado, en las actividades de artesanía y sus áreas especializadas (Manzanilla, 1986), los intercambios y el comercio (por ejemplo Arnauld, 1990b; McAnany, 1993; Demarest et al., 2014) u otros aspectos, para un sinnúmero de sitios. Casi todas las monografías arqueológicas incluyen capítulos dedicados al estudio de esos recursos, incluyendo los volúmenes de Toniná (Becquelin y Baudez 1979-82, Becquelin, Taladoire et al. 1990). Sin embargo, a diferencia de 
lo que se hace en Teotihuacan donde se desarrollan estudios holísticos en el contexto de grupos residenciales o de barrios (Manzanilla, 1993, por ejemplo), o en México-Tenochtitlan, en el contexto de las excavaciones del Templo Mayor (López Luján et al., 2003), son todavía escasos los estudios sistemáticos de esos aspectos y de sus interacciones en un mismo sitio o en una misma entidad maya. El trabajo de Webster (2005) en el valle de Copán constituye uno de los pocos ejemplos con una perspectiva diferente. Queremos, en este trabajo, sintetizar los datos disponibles en el caso específico de Toniná, para tratar de entender las bases económicas de su desarrollo. ${ }^{1}$ Por supuesto, las conclusiones aquí obtenidas sólo son pertinentes para Toniná, pues el método daría ciertamente resultados diferentes para otras entidades.

\section{La entidad política de Toniná: el valle de Ocosingo}

Ubicado en el valle de Ocosingo, Toniná es uno de los sitios mayas más occidentales, que se encuentra además en la zona de transición entre las tierras bajas y las tierras altas, a $900 \mathrm{msnm}$ (Becquelin y Baudez, 1979-82), al límite entre la zona caliente y la templada. Ocosingo corresponde al amplio sinclinal de Simojovel, orientado noroeste-sureste, que forma parte del vasto conjunto sedimentario terciario y cuaternario plegado de Chiapas (Puig y Usselmann, 1982, 1990). Las vertientes norte y oeste se componen de amplios macizos de piedra caliza, que alcanzan rápidamente los $2000 \mathrm{msnm}$, a unas horas de camino apenas del propio valle. $^{2}$ En la parte central del sinclinal, dos cadenas casi paralelas de lomas de piedra arenisca delimitan una zona baja de tierras arcillosa-arenosas que corresponden al drenaje del Río Jataté y de sus principales afluentes, el Chantechac y el Río de la Virgen. ${ }^{3}$ Esos ríos y los numerosos arroyos que bajan de las tierras altas vecinas transportan hacia el valle, en sus aluviones, una gran cantidad de cantos rodados de piedras duras y de rocas volcánicas o metamórficas de la formación El Bosque, incluyendo piedras verdes, de acceso fácil para los habitantes. ${ }^{4}$

El clima del valle es clasificado como templado-húmedo, con una temperatura media anual de $24.3^{\circ}$ (enero es el mes más frío, con $22^{\circ}$; mayo el más caliente, con $26^{\circ}$ ). Por supuesto, el clima cambia conforme con la altitud, en las vertientes

\footnotetext{
${ }^{1}$ Para este trabajo, nos apoyamos principalmente en los datos recopilados en las cinco temporadas de excavación del proyecto francés (1972-81), pero tomamos en consideración la información disponible sobre las excavaciones dirigidas por el arqueólogo Juan Yadeun Ángulo. Aunque son pocos los elementos publicados todavía sobre la cultura material, lo que permite suponer posibles modificaciones de los datos y de proporción del material, dudamos que modifiquen de manera sustancial los conocimientos disponibles.

${ }^{2}$ Durante los reconocimientos de las temporadas de 1979-80, tuvimos la oportunidad de visitar varios sitios ubicados en las alturas, como Tzajalchib $(1440 \mathrm{msnm})$ o Chiclaianhuitz (1600 msnm), de levantar su plano y de recoger material de superficie, lo que nunca necesitó más de un día de trabajo.

${ }^{3}$ Es necesario mencionar aquí que esos ríos no son navegables.

${ }^{4}$ Las identificaciones petrográficas en secciones delgadas efectuadas por J. Butterlin confirmaron esta procedencia (Puig y Usselmann, 1990: 1500).
} 
norte y oeste, pero las temperaturas no difieren mucho entre el valle mismo y los sitios secundarios localizados sobre las lomas circundantes. La cantidad media anual de precipitaciones alcanza $1803.7 \mathrm{~mm}$, y aún en los meses de enero y febrero de la temporada seca se registra cierta cantidad de lluvias (alrededor de los $50 \mathrm{~mm}$ en febrero), generalmente asociadas con los nortes.

Este clima y la geomorfología del valle permiten el crecimiento de especies boreales (pinos, robles) en las partes altas, y neotropicales (anona, chayote, ramón, frutales, ficus, algodón y hasta caña en la época colonial) ${ }^{5}$ en el valle. Incluso el nombre de Ocosingo refleja la riqueza local de pinos. ${ }^{6}$ Puig (Puig y Usselmann, 1982, 1990) registra la presencia actual de numerosas frutas tropicales, como naranjas, zapotes, aguacates, mangos, y subraya además la posibilidad de realizar en el valle dos cosechas anuales, debido a la abundancia de agua y a la fertilidad de la tierra en las partes bajas. Además crecen allí naturalmente otras especies vegetales útiles, plantas medicinales (ajenjo, fresno) y comestibles (chiles, guayaba, yuca) (Puig y Usselmann, 1982, 1990). Cabe señalar la presencia natural de algodón (Gossypium) y de diferentes tipos de ficus (Ficus glabrata, Ficus involuta), para la fabricación de papel. Los diferentes reconocimientos sistemáticos no permitieron identificar el más mínimo indicio de agricultura intensiva, tales como terrazas o camellones.

Este medio natural rico y variado proporciona a los habitantes una amplia gama de recursos básicos complementarios. La piedra caliza está siempre disponible para la arquitectura o para la fabricación del estuco, mientras que las piedras areniscas, fáciles de trabajar, constituyen la base del arte escultórico ${ }^{7}$ y de la elaboración de artefactos. Los cantos rodados abundan para la industria lítica. Las arcillas de la parte baja del valle sirven para la cerámica. Uno de los recursos notablemente ausente es la sal.

Los pinos y los robles proporcionan la madera necesaria para cocinar, calentarse en los meses más fríos y fabricar el estuco para los edificios y los relieves, las tareas arquitectónicas y la edificación de las chozas; mientras que las palmas pudieron servir para los techos. Está hipótesis ya había sido formulada por Blom (y Lafarge, 1927, II: 266, citado por Ayala Falcón, 1995: 55). La madera de pino se aprovechaba también como antorchas, su resina para las ofrendas y tal vez su follaje para los rituales. ${ }^{8}$

\footnotetext{
${ }^{5}$ Se registraron varios ingenios antiguos durante el reconocimiento de las temporadas de 1979-80.

6 De ocotl: "pino" en nahuátl. Ocosingo significaría “el lugar del señor de los pinos” o, más sencillamente, "lugar de los pinitos".

${ }^{7}$ El sarcófago de la sepultura IV-1 también está hecho de piedra arenisca. El segundo sarcófago descubierto en 2010 por los arqueólogos mexicanos parece hecho de la misma piedra <http://www. inah.gob.mx/boletin/14-hallazgos/4118>.

${ }^{8}$ Aunque resulta imposible comprobar arqueológicamente el uso de agujas de pino para cubrir el piso de las iglesias durante las fiestas, es una práctica bien documentada entre los tzeltales y los tzotziles.
} 
En cuanto a la fauna, los ríos son ricos en moluscos, tortugas, pescados y otros recursos acuáticos, entre ellos, los juncos de las zonas pantanosas, que pueden facilitar la fabricación de cestas y de petates. Se recuperaron en las excavaciones grandes cantidades $(97.8 \%$ del total de moluscos) de moluscos del genero dulceacuícola comestible Pachychilus (Valentín M. y Polaco, 1990). ${ }^{9}$ La diversidad ecológica constituye un medio natural favorable para casi todas las especies, mamíferos (venados, perros, felinos, roedores), aves (guacamayas, guajolotes) y reptiles (serpientes, tortugas). La existencia posible de abejas sólo se documentó iconográficamente, y no se puede descartar una convención simbólica, compartida con la plástica maya de otras entidades. El medio resulta favorable para la presencia de colmenas, lo que permitiría la producción de miel, de cera y de balché, la bebida alcohólica tradicional. De la fauna identificada en las excavaciones (Álvarez, 1982; Álvarez, Ocaña y Valentín M., 1990), sólo el tapir, el tepezcuintle, el mono araña y el quetzal constituyen especies importadas, pero de zonas vecinas.

\section{La entidad política de Toniná: el territorio}

En un artículo anterior (Taladoire, 2015), hemos tratado de definir el territorio controlado por la entidad de Toniná, aun si, por supuesto, no se trata de un dominio económico estricto, sino de un sistema de relaciones socio-políticas basadas en parentesco, alianzas y el control de poblaciones (Golden y Scherer, 2013). Como lo nota Demarest (et al., 2014), este sistema resulta pertinente para las entidades mayas clásicas de las tierras bajas como Yaxchilán y Piedras Negras, donde existen relativamente pocas diferencias internas en el medio ambiente. A diferencia de Golden y Scherer, y de acuerdo con los estudios realizados en Cancuén (Demarest et al., 2014; Forné et al.; 2014), consideramos que el control de las poblaciones de zonas ecológicas diferentes, que corresponde a la situación de Toniná, también facilita el acceso a sus recursos, lo que implica consecuencias económicas. Como Toniná, Cancuén se ubica en la zona transicional entre las tierras altas y bajas, pero en un punto clave de control del eje fluvial estratégico del Usumacinta y de sus afluentes, lo que le permitió desarrollar una actividad productiva de artesanía y de control de intercambios, con repercusiones sobre el carácter socio-político de sus élites. Demarest escribe (2014: 188) que los debates sobre la naturaleza del poder en las ciudades mayas se focalizan sobre diversos aspectos "including the degree of elite involvement in various aspects of economy, such as exchange, production and infrastructures". Al contrario de otras entidades mayas, como lo demostramos más adelante, resulta evidente la implicación de las élites de Cancuén y de Toniná en la búsqueda de control del acceso a los recursos básicos (sal y obsidiana) y de prestigio (jade).

De acuerdo con los datos disponibles, el territorio de Toniná se extendería, en un eje aproximadamente sureste-noroeste, conforme con el eje del sinclinal de

${ }^{9}$ El nombre local es jute. 
Simojovel y la cuenca del río Jataté, desde los alrededores de Xoc al sureste, en el valle bajo del Jataté, hasta por lo menos la región de Tila al noroeste, cerca de Palenque y de Tabasco (ver Mapa 1). No podemos afirmar que Xoc, al límite de la selva lacandona, estuviese sometido a Toniná (Ekholm-Miller, 1973).

Hacía el noroeste, el territorio incluía las áreas de Chilón y Bachajón, y probablemente de Tumbalá, tal vez controlada por la entidad todavía mal identificada de Sib'ikte, aliada de Toniná (Taladoire, 2015; Andrieu et al., 2012). Un artículo reciente de Sheseña Hernández y Tovalín-Ahumada (2014) apoya esa interpretación y hasta propone que el sitio de Bolonkin, cerca de Chilón, podría ser Sib'ikte. No sabemos si Tila se encontraba bajo el dominio de Toniná, de Palenque o si esta región era una zona de conflicto entre las dos ciudades rivales (Bassie-Sweet, 2015). La entidad de Toniná se extendía así paralela a la amplia cadena montañosa de la Sierra Norte de Chiapas, localizada al noreste y difícil de atravesar. ${ }^{10}$ Los únicos sitios documentados, como Rancho Búfalo, se ubican al pie oriental de esta sierra, tal vez relacionados con la entidad de Piedras Negras (Jiménez Álvarez et al., 2014). Falta todavía definir los límites hacia el suroeste, en dirección de los Altos de Chiapas (Culbert, 1965; Paris, Taladoire y Lee Jr., 2013, 2015).

El control de este extendido territorio facilitaba un acceso simultáneo a los recursos geológicos, faunísticos y florísticos complementarios de las tierras bajas tropicales ${ }^{11}$ y de las tierras altas chiapanecas. Entre esos últimos figuran el ámbar, posibles yacimientos de jadeíta o de piedras verdes y plumas de quetzal. Los yacimientos de ámbar son numerosos en Chiapas, sobre todo en las zonas de Totolapa y de Huitiupan-Simojovel (Lowe, 2001, 2004). Simojovel queda cerca de Yajalón, bajo el dominio de Toniná. Los zoques, ubicados en Tabasco, Chiapas y parte de Oaxaca, jugaron un papel importante en la explotación de este recurso; intercambiaban los recursos de su territorio preferentemente con el área zapoteca, como lo demuestra de manera simultánea la frecuencia del ámbar en Oaxaca, en la Tumba 7 de Monte Albán, por ejemplo (Caso, 1969; Lowe, 2001, 2004), y su ausencia en la mayoría de las ciudades mayas clásicas. La única excepción es el cenote de Chichén Itzá, en el Posclásico (Lowe, 2001, 2004). Sólo se encontraron objetos de ámbar en Chiapa de Corzo y en sitios de las tierras altas (Kaminaljuyú, Tenam Puente, Cimientos de Las Margaritas).

La presencia de jadeíta, de jade o de piedras verdes en la región de Chalchihuitán es todavía un tema muy controvertido, ${ }^{12}$ y se necesitan futuras investigaciones al respecto. Pero es muy probable que existieran yacimientos de piedras verdes (serpentina, jadeíta, tal vez de baja calidad) en esta área, que se ubica a escasa distancia de Toniná, en los Altos de Chiapas.

10 A la fecha, esta región no ha sido el objeto de suficientes estudios para entender su ocupación prehispánica.

${ }^{11}$ El tapir o el mono araña, por ejemplo.

12 Walsh, conversación personal, 2010; Andrieu, conversación personal, 2011. La existencia de este yacimiento acaba de ser confirmada (H. N. Bernard, conversación personal, septiembre de 2015). 


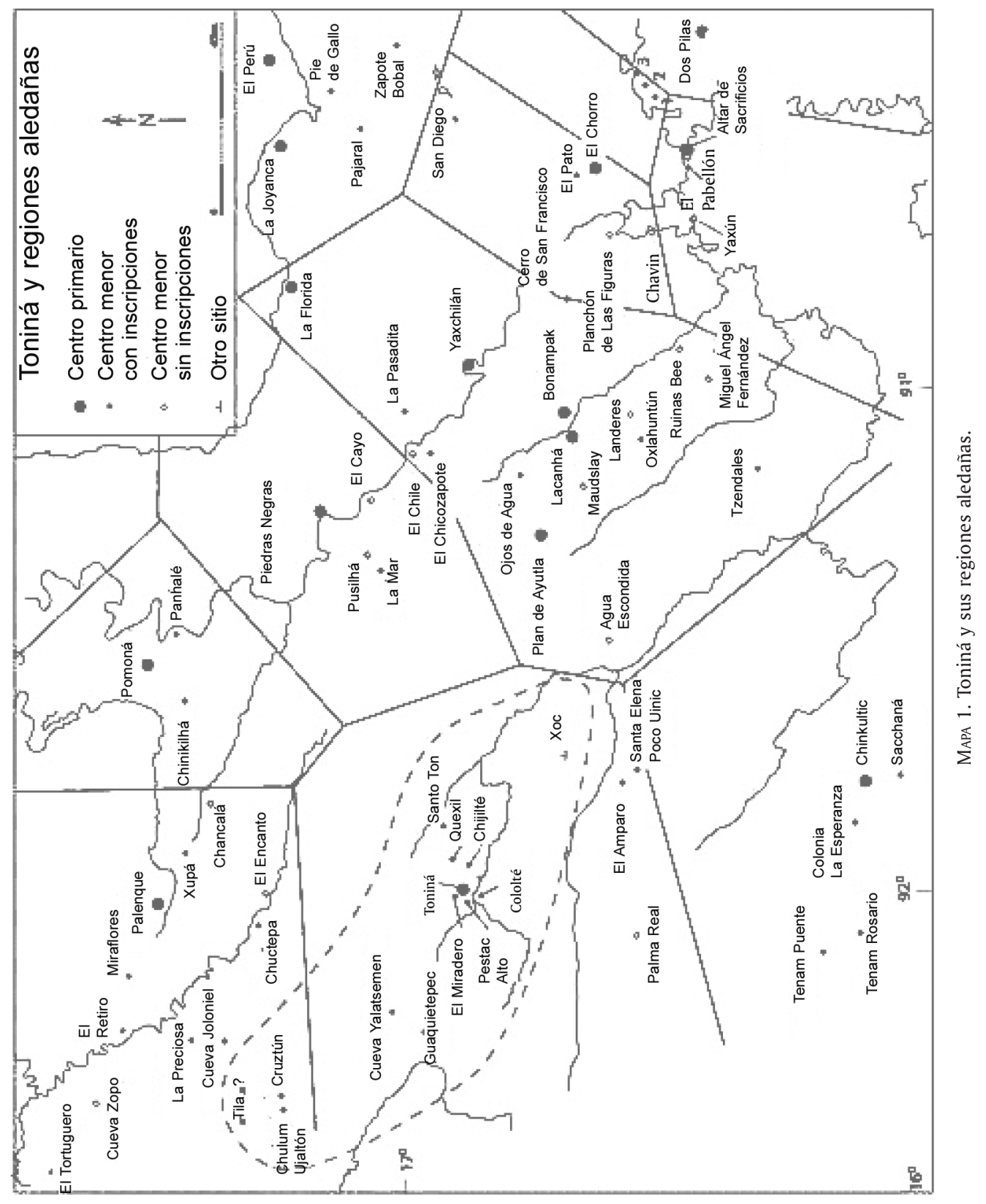


Por otro lado, el nombre chol de Tumbalá es K'uk' Witz, "la montaña de los quetzales", debido a la abundancia de estas aves en un medio ambiente particularmente favorable (Bassie-Sweet, 2015). Tumbalá pertenecía a la entidad de Toniná. En su territorio propio, o en áreas con las cuales intercambiaban, los habitantes de Toniná tenían entonces un acceso directo a diferentes recursos ausentes, codiciados del valle de Ocosingo.

Debemos, además, recordar que el estudio de los sistemas de intercambio en el Chiapas posclásico y colonial (Navarrete, 1973: 63) define una ruta que une Ciudad Real (San Cristóbal de Las Casas) con Tabasco. Esta ruta pasa por Huixtán, Oxchuc, Guaquitepec, Sitalá, Chilón, Yajalón y Tumbalá. Atraviesa entonces casi todo el territorio controlado por Toniná (Taladoire, 2015), para desembocar al norte en las ricas planicies aluviales de Tabasco donde crecen las especies vegetales que proporcionan otros productos codiciados como el hule o el cacao. Ayala Falcón (1995) recuerda además que dos de las rutas de intercambio entre el Altiplano de México y las tierras bajas mayas atraviesan precisamente Tabasco. Navarrete (1973) añade que Tila era un centro de culto importante para la gente de Tabasco en la época colonial, entre ellos los zoques, aunque resulta difícil comprobarlo para los períodos prehispánicos.

Por otro lado, el valle de Ocosingo colinda directamente con los Altos de Chiapas, lo que facilitaba los intercambios (Paris, Taladoire y Lee, 2013, 2015). Al contrario, el camino que va del valle hacia la región de Comitán es largo y difícil, dificultando las posibles relaciones. ${ }^{13}$

Con base en algunas evidencias epigráficas (Ayala Falcón, 1997; Wichmann y Lacadena, 2005), hemos sugerido (Taladoire, 2015) que tal vez los habitantes de Toniná pertenecían al grupo linguístico tzeltal'ano. Eso explicaría, por un lado, sus lazos políticos y económicos con las entidades tzeltales y tzotziles de los Altos de Chiapas (Paris, Taladoire y Lee Jr., 2013, 2015), y, por otro, quizá su hostilidad hacia las demás entidades de las tierras bajas de tradición cholana como Palenque. Otras evidencias sugieren intercambios regulares, en la zona de Tila, con los zoques, como veremos más adelante.

Finalmente hay que tener en cuenta el aspecto demográfico. De acuerdo con los resultados obtenidos en los diversos reconocimientos (Becquelin, Taladoire et al., 1990; Becquelin, Michelet y Taladoire, 1994), y conforme con la proporción usual de 5.6 habitantes por plataforma residencial, tendríamos una población apenas superior a 3000 personas en el propio valle, lo que parece una cifra muy baja (Taladoire, 2008, 2015). Considerando el territorio completo de la entidad de Toniná, podemos suponer una población total entre 5000 y 10000 personas. Debemos recordar incluso que, para la ciudad de Palenque, durante las fases Otolúm-Murciélagos (650-750 d.C.) y Balunté (750-850 d.C.), Liendo Stuardo (2011: 78) sólo llega a la cifra ligeramente superior de 6000 a 8000 habitantes.

\footnotetext{
${ }^{13}$ Este camino era, hasta la construcción de la carretera San Cristóbal-Ocosingo, el acceso tradicional, lo que contribuyó al largo aislamento del valle.
} 
En resumen, los recursos naturales disponibles resultan más que suficientes para abastecer las necesidades vitales de sus ocupantes. Aunándose a la riqueza intrínseca y a la diversidad de productos naturales del mismo valle de Ocosingo, el territorio de la entidad política complementa el acceso a bienes codiciados, sobre todo en un contexto de intercambio con comunidades de los Altos de Chiapas y de las planicies de Tabasco.

\section{Las aportaciones de los datos arqueológicos}

No se necesita volver a hablar aquí de las actividades arquitectónicas, ni del arte escultórico, que ya discutimos, salvo para insistir sobre la disponibilidad local de los recursos indispensables. Al respecto, Toniná no se diferencia fundamentalmente de las demás ciudades mayas. La única posible excepción sería tal vez la utilización del chicozapote para elaborar dinteles, por ejemplo, el dintel de la Estructura E5-5 (Stephens y Catherwood, 1969: 256, citado por Ayala Falcón, 1995: 14, 54). Pero si no se encuentra esta madera en el valle, se puede obtener en abundancia en la selva tropical, en territorios controlados por Toniná.

Debemos aún considerar el aspecto particular de los pigmentos utilizados en las pinturas murales documentadas en el sitio (Yadeun, 1993, 2011: 56; Mateos González, 1996, 1997). Esta última autora subraya la relativa carencia de los pigmentos y su pobreza, ya que sólo identificó el carbonato de calcio para el blanco, el carbón para el negro, la limonita para el ocre, la hematita para el rojo y el añil o la atapulgita para el azul. Salvo los dos últimos componentes, todos los demás son de fácil adquisición en el valle y sus alrededores. Es muy probable que la atapulgita haya sido importada de Campeche o de Tabasco.

\section{La cerámica}

Como lo nota Becquelin (Becquelin y Baudez, 1979-82), aunque la cerámica de Toniná pertenece indudablemente, desde sus inicios (fases Wach, May e Ixim, Cuadro 1), a la esfera del Petén, presenta ciertas especificidades locales (los tipos Pamtelá blanco, Quechil blanco acanalado, Mosil rojo inciso, por ejemplo), que la diferencian ligeramente. La cerámica doméstica es de fabricación local, pero no se descubrieron talleres de alfarería. Lo mismo vale para las vajillas decoradas, aunque es posible contemplar algunas adquisiciones foráneas (tipos Laltic naranjo polícromo, Cahuitz naranjo polícromo, Jawalton crema polícromo) tal vez de la cuenca del Usumacinta (Becquelin y Baudez, 1979, I: 208). Ante la falta de estudios de pastas, esta posibilidad es sólo una hipótesis.

Al momento de definir la secuencia cerámica de Toniná (Becquelin y Baudez, 1979-82), el concepto de Clásico Terminal estaba todavía muy mal definido (Demarest, Rice y Rice, 2004). Esa fue una de las razones, además de la existencia 


\begin{tabular}{|l|c|c|}
\hline Preclásico Tardío & Wach & $0-300$ d.C. \\
\hline Clásico Temprano & May & 330-550 d.C. \\
\hline Clásico Tardío & Ixim & 600-910 d.C./ 600-840 d.C. \\
\hline Clásico Terminal & Ixim-Chenek & $840-1000$ d.C. \\
\hline Posclásico Temprano & Chenek & $1000-1250$ d.C. \\
\hline Posclásico Tardío & Chib & $1250-1528$ d.C. \\
\hline
\end{tabular}

CuAdro 1: Esquema cronológico revisado de la secuencia de Toniná

del Monumento 101 (que lleva la fecha equivalente a 909), para asignar a la fase Ixim una duración hasta el 910 d.C. Con el descubrimiento, en 1980, de vestigios de actividad arquitectónica en la segunda terraza (Estr. F5-2), que complementan los datos estratigráficos del basurero del Grupo F4 (Arnauld, 1990a), y posteriormente, con las investigaciones de Yadeun (1992, 1993), resulta confirmada una ocupación continua del sitio por lo menos hasta fines del siglo $\mathrm{x}$. Al contrario, los estudios epigráficos atestiguan una interrupción de las actividades escultóricas entre los reinos del Dirigente 9 (Uh Chapat, 837 d.C.) y del Dirigente 10, documentados por los Monumentos 158 y 101 (Martin y Grube, 2000: 189). Resulta entonces posible sugerir una fase de transición Ixim-Chenek, que abarcaría el período de 840-1000 (y quizá más adelante), es decir, un Clásico Terminal en Toniná, más conforme con la periodización actual.

Por supuesto, cuando se estableció la secuencia cerámica de Toniná, ${ }^{14}$ Becquelin no disponía de los datos comparativos de sitios como Yaxchilán o Piedras Negras, sin volver a mencionar algunas incógnitas sobre la secuencia de Palenque. ${ }^{15}$ No nos pareció pertinente referirnos a la secuencia de Cancuén (Forné et al., 2011), por estar demasiado alejado del valle de Ocosingo. De todos modos, la lectura de los estudios cerámicos de Forné demuestra que ella tampoco hace referencia a Toniná. El examen preliminar de la secuencia de Piedras Negras (Muñoz, 2006) permite evidenciar que este autor nunca se refiere a la cerámica de Toniná, ni en sus comparaciones, ni en su bibliografía. El estudio de su tipología sólo permitió identificar varios tipos comunes a diferentes entidades, naturalmente los polícromos o escasas piezas de los grupos Gris Fino y Anaranjado Fino, también importadas en Piedras Negras. Pero no hemos encontrado ninguna similitud con

${ }^{14}$ A falta de datos sobre el material cerámico de las últimas excavaciones, no podemos descartar la identificación de nuevos tipos, una mejor definición de otros, ni nuevos estudios comparativos. Considerando los datos obtenidos en las cinco temporadas y las publicaciones de Yadeun (1993), dudamos mucho de que la secuencia básica se haya modificado drásticamente, salvo tal vez para una definición más precisa de la fase de transición Ixim-Chenek.

${ }^{15}$ Hay que recordar también que no disponemos todavía de secuencias precisas para sitios como Bonampak, Sak T'zi, Xoc o Santa Elena Poco Uinic, con los cuales Toniná hubiera podido mantener relaciones. 
los tipos cerámicos característicos de Toniná. Merece mencionarse que los estudios cerámicos del Proyecto Arqueológico Busiljá-Chocoljá (Jiménez Álvarez et al., 2014: 189) permitieron identificar una posible semejanza entre el tipo Marqués crema y el Caana Blanco Grabado de Toniná.

Para Yaxchilán, el estudio de López Varela (1989) incluye varias referencias a la secuencia de Toniná, citada en la bibliografía. Pero todas las comparaciones se refieren a los grupos Gris Fino (Chicxulub inciso, Poité inciso, Telchac compuesto) y Anaranjado Fino del Clásico Terminal (Pabellón modelado e inciso, Provincia plano-relieve, Tumba negro sobre naranja, Silhó naranja), o sea, cerámica importada, como en Toniná o en Piedras Negras. En ambos sitios, entonces, la secuencia cerámica confirma la ausencia de relaciones con Toniná y el carácter local de la producción alfarera.

Por el contrario, a fines del Clásico Tardío y en la fase de transición Ixim-Chenek, es indudable la presencia de cerámica importada, aunque en pocas cantidades, principalmente de los grupos Gris Fino y Anaranjado Fino (Becquelin y Baudez, 1979-82: 208; Becquelin, Taladoire et al., 1990). Del grupo Gris Fino, destacan los tipos Chablekal gris (17 tepalcates en las temporadas 1 y 2 ; dos recipientes y muchos tepalcates en las temporadas 4 y 5), Chicxulub inciso (23 tepalcates), Cholul acanalado (un recipiente y tres tepalcates) y Telchac compuesto (9 tepalcates). En comparación con otras entidades (Palenque, Cancuén, el Perú Waká), esta muestra queda muy reducida. ${ }^{16}$ Considerando que el tipo Chablekal gris sería originario de la región de Palenque y de Jonuta (Rands, Bishop y Sabloff, 1982; Bishop, Sears y Blackman, 2005), y fechado al Clásico Tardío (750-850), esta relativa escasez no resulta tan sorprendente. En efecto, su obtención podría resultar de intercambios ocasionales, quizá con Jonuta, de las tentativas de control por Toniná de la región de Tila, o posiblemente del tributo consecutivo a la victoria de K'inich Tuun Chapat sobre Palenque, a fines del siglo VIII (Martin y Grube, 2000: 187).

Del grupo Anaranjado Fino, destacan los tipos Pabellón modelado e inciso ( 9 tepalcates), Tumba negro sobre naranja (4), Provincia plano-relieve (dos recipientes), Poité inciso (1), y para la fase de transición, Silhó naranja (17\% de la muestra de las dos primeras temporadas) y Matillas naranja (dos recipientes). Como escribe Becquelin (1979-82: 208), esas importaciones proceden con probabilidad de Tabasco o de la Chontalpa, una región con la cual, como ya vimos, Toniná tenía relaciones de intercambio. De manera secundaria para nuestro propósito, el aumento de las importaciones en la fase de transición y al principio de la fase Chenek confirma la resiliencia de la población local, después de la destrucción de la ciudad.

Otras importaciones son las piezas del grupo Tohil Plumbate (4.9\% del material de la fase final en las cinco temporadas) de la costa Pacífica. Este grupo parece particularmente bien representado en las excavaciones de Yadeun (2001: 49), en relación con la fase Chenek, después de la caída de la ciudad o por lo menos

\footnotetext{
${ }^{16}$ Chloé Andrieu, conversación personal, 2015.
} 
de su dinastía. Yadeun ilustra en una foto varias ollas globulares plomizas, que, según sus comentarios, contenían los restos quemados de varios individuos. También importadas son las piezas del tipo Huistán duro originario de los Altos de Chiapas (Culbert, 1965). Las relaciones con los Altos de Chiapas parecen reforzarse en la fase Chib del Posclásico Tardío, sobre todo en el sitio de Tzajalchib, ${ }^{17}$ con la aparición de otros tipos característicos como San Gregorio burdo (Paris, Taladoire y Lee Whiting, 2013, 2015).

Aunque notables, esas importaciones no representan cantidades muy importantes, sino que confirman las relaciones privilegiadas de Toniná y del valle de Ocosingo con las culturas localizadas al noroeste y al oeste de su territorio.

\section{La lítica}

En su contribución sobre la lítica del valle de Ocosingo, Rodriguez-Loubet (1990: 1794) escribe: "Los vestigios líticos del valle de Ocosingo sugieren un especie de microcosmos funcionando sobre sí mismo y parcialmente por sí mismo, de acuerdo con particiones sociales muy estrictas". Sintetizando los datos de todas las temporadas, presenta los resultados siguientes:

- Lítica pulida. La mayoría de los artefactos aprovechan los recursos locales. La casi totalidad de los metates y de las manos están hechas de piedra arenisca, así como muchos utensilios básicos (morteros, martillos, pulidores y otros). Sólo algunos objetos especializados están fabricados en otras materias primas, pero casi siempre disponibles en el valle como cantos rodados de piedras duras. En las cinco temporadas, se registró un total de 32 piezas bifaciales hechas con piedras metamórficas (diorita, serpentina, jadeíta) o volcánicas, a veces disponibles localmente, en otros casos con piedras importadas. Destaca la presencia de algunos artefactos de basalto o de esquisto, dos materias primas ausentes del valle. Como no se identificó ningún taller, resulta posible la importación de piezas ya terminadas de los Altos de Guatemala. Los escasos objetos de esquisto se pueden considerar de prestigio. Entre ellos figuran dos espejos, una placa anular plana con glifos incisos, expuesta en el museo de sitio, y un hacha pulida de $20 \mathrm{~cm}$, también con inscripciones jeroglíficas (Graham, 2006: 128. Miscellaneous 6). ${ }^{18} \mathrm{~A}$ este conjunto podemos añadir un hacha de piedra verde (Yadeun, 1993: 43), aunque este autor no precisa si se trata de un utensilio o de un hacha votiva.

- Lítica tallada. Rodriguez-Loubet (1990) y Baudez (Becquelin y Baudez, 1979-82) registran la presencia de numerosos utensilios burdos en pe-

\footnotetext{
${ }^{17}$ No tenemos ingún indicio de presencia humana notable en Toniná mismo.

${ }^{18}$ Esta hacha se encuentra en el museo de sitio.
} 
dernal y en cuarcita, disponibles en la región, lo que implica una fabricación local, quizá doméstica. La obsidiana representa el único ejemplo comprobado de importación de materia prima. Durante las cuarta y quinta temporadas, se recuperó un total de 5145 piezas líticas, de las cuales las de obsidiana representan un $29 \%$. La mayoría de los artefactos de obsidiana son de color gris, lo que sugiere una procedencia de los Altos de Guatemala, posiblemente de la región de Tajumulco, de San Martín Jilotepeque o del Chayal (Becquelin y Baudez, 1979-82: 1036). Se nota la predominancia de navajas y la casi ausencia de desechos de talla. A falta de indicios pertinentes, Rodriguez-Loubet (1990) supone una importación bajo la forma de núcleos prismáticos ya preparados. La misma hipótesis ha sido propuesta para Cancuén (Demarest et al., 2014). La obsidiana verde de Hidalgo sólo representa un porcentaje mínimo, 2.5\% (34 fragmentos). La proporción es más o menos equivalente para las temporadas anteriores (34 fragmentos de los 1303 ejemplares recuperados). Esta relativa escasez es un rasgo compartido por la mayoría de las ciudades mayas clásicas (Clark, 1986). ${ }^{19}$ Merece mencionarse la ausencia de obsidiana negra de Zaragoza, con frecuencia asociada a las cerámicas de pasta fina, y que se encuentra en grandes cantidades en sitios del Clásico Tardío en Tabasco y Veracruz. ${ }^{20}$ Esta ausencia contradice nuestras hipótesis de relaciones privilegiadas de Toniná con las planicies de Tabasco. Pero, de manera simultánea, el abastecimiento regular de la ciudad desde las fuentes guatemaltecas no necesitaba la adquisición de materias primas de otros yacimientos.

\section{Artefactos diversos y ornamentos}

Para empezar, es indispensable notar la presencia de dos yugos fragmentados ${ }^{21}$ encontrados en los alrededores de la acrópolis (Becquelin y Baudez, 1979-82) en los grupos residenciales de la primera terraza (Operaciones III y V-Oeste). Tales hallazgos son excepcionales en las tierras bajas mayas, y sólo podemos documentar el descubrimiento comparable de 52 fragmentos de yugos y de hachas votivas en Palenque (Cruz Romero 2012). ${ }^{22}$ Sheseña y Lee Whiting (2004)

\footnotetext{
${ }^{19}$ Chloé Andrieu (comunicación personal, 2015) considera, sin embargo, que esas cantidades resultan importantes, en comparación con otras ciudades, y sobre todo para el Clásico Tardío. La presencia de obsidiana verde aumenta principalmente durante el Clásico Terminal. Como hemos dicho arriba, la diferencia entre ambos períodos no resultó posible en aquel entonces, pero, en general, buena parte de los fragmentos de obsidiana verde provienen de sitios fechados para la fase Ixim.

${ }^{20}$ Chloé Andrieu, conversación personal, 2015.

${ }^{21}$ Uno de ellos sería un yugo miniatura.

${ }^{22}$ Cabe mencionar que los fragmentos de yugos en Palenque no se encontraron en contexto, sino en los rellenos de plataformas o de edificios.
} 
publicaron también un yugo completo incrustado de conchas, sin procedencia precisa, que fue supuestamente descubierto en los alrededores de Chilón. Casi nunca se descubrieron yugos en otros sitios de las tierras bajas mayas. ${ }^{23} \mathrm{La}$ presencia de yugos en esas márgenes occidentales del área maya se puede relacionar con posibles aportaciones del sur de Veracruz o de Tabasco, donde se documentaron varios descubrimientos de tales objetos (Kurosaki Maekawa, 2006; Roose, 2006). De nuevo, encontramos una posible conexión de la entidad con Tabasco, al noroeste.

Aunque su procedencia es dudosa, debemos también mencionar la caja de piedra fina ilustrada por Martin y Grube (2000: 187) que menciona en sus inscripciones al dirigente K'inich Tuun Chapat de Toniná. Nada permite asegurar que proviene de Toniná (Coe, 1973: 33).

Principalmente en las sepulturas (Cuadro 2) y en los depósitos rituales (Cuadro 3) se descubrieron varios artefactos, en su gran mayoría importados.

\begin{tabular}{|l|c|c|c|c|c|c|c|c|}
\hline $\begin{array}{c}N^{\circ} \text { Sepultura } \\
\text { y fecha }\end{array}$ & Jadeíta & $\begin{array}{c}\text { Piedra } \\
\text { verde }\end{array}$ & Pirita & Cobre & Oro & Conchas & Coral & Otros \\
\hline I-1 (PCT) & $\mathrm{X}$ & $\mathrm{X}$ & & & & & & \\
\hline III-1 (CT) & $\mathrm{X}$ & $\mathrm{X}$ & $\mathrm{X}$ & $\mathrm{X}$ & & & & \\
\hline III-8 (CT) & & $\mathrm{X}$ & & & & & & \\
\hline IV-1 (CT) & $\mathrm{X}$ & $\mathrm{X}$ & & $\mathrm{X}$ & & & & \\
\hline IV-2 (CT-PC) & $\mathrm{X}$ & & & $\mathrm{X}$ & & & & $\begin{array}{c}\text { Diente } \\
\text { de tiburón }\end{array}$ \\
\hline IV-3 (CT-PC) & $\mathrm{X}$ & & $\mathrm{X}$ & & & $\mathrm{X}$ & & $\begin{array}{c}\text { Diente } \\
\text { de tiburón }\end{array}$ \\
\hline IV-4 (CT) & $\mathrm{X}$ & $\mathrm{X}$ (obs.) & & & & $\mathrm{X}$ & & Tecali \\
\hline IV-5 (CT) & $\mathrm{X}$ & & & & & & & \\
\hline IV-6 (CT) & $\mathrm{X}$ & $\mathrm{X}$ & & & & & & \\
\hline IV-7 (PCA) & $\mathrm{X}$ & & & $\mathrm{X}$ & $\mathrm{X}$ & Spondylus & & \\
\hline IV-8 (PCA) & $\mathrm{X}$ & & & $\mathrm{X}$ & $\mathrm{X}$ & $\mathrm{X}$ & & \\
\hline IV-9 (PCA) & $\mathrm{X}$ & & & $\mathrm{X}$ & $\mathrm{X}$ & & & \\
\hline VIII-1 (CT) & $\mathrm{X}$ & & & & & & & \\
\hline VIII-2 (CT) & $\mathrm{X}$ & & & & & & & \\
\hline Santa Teresa (CTe) & $\mathrm{X}$ & & & & & & & \\
\hline Laltic 6 (CT) & $\mathrm{X}$ & & & & & & $\mathrm{X}$ & \\
\hline Vayeltaj 3 (CT) & $\mathrm{X}$ & & & & & & & \\
\hline
\end{tabular}

CuAdro 2. Artefactos no cerámicos encontrados en las sepulturas del valle de Ocosingo.

(CTe: Clásico Temprano, CT: Clásico Tardío, PC: Posclásico,

PCA: Posclásico Antiguo, PCRT: Posclásico Tardío)

${ }^{23}$ Debemos mencionar un ejemplo en Kohunlich, y el posible yugo de madera encontrado en Tikal por Guillemin (1968). 


\begin{tabular}{|l|c|c|c|c|c|c|c|}
\hline $\begin{array}{c}\text { Depósito } \\
\text { ritual }\end{array}$ & Jadeíta & $\begin{array}{c}\text { Piedra } \\
\text { verde }\end{array}$ & Pirita & Metal & Conchas & Ámbar & Otros \\
\hline I-1 (PCA) & & $\mathrm{X}$ & & & & $\mathrm{X}$ & $\begin{array}{c}\text { Cristal } \\
\text { de roca }\end{array}$ \\
\hline II-3 (CT) & $\mathrm{X}$ & $\mathrm{X}$ & & $\mathrm{X}$ & & & \\
\hline III-1 (CT) & $\mathrm{X}$ & $\mathrm{X}$ & $\mathrm{X}$ & & Spondylus & & \\
\hline III-2 (CT) & & $\mathrm{X}$ & $\mathrm{X}$ & & & & $\begin{array}{c}\text { Diente } \\
\text { de tiburón }\end{array}$ \\
\hline IV-1 (CT) & $\mathrm{X}$ & & & & Spondylus & & Granate \\
\hline VIII-1 (CT) & $\mathrm{X}$ & & & & & & \\
\hline VIII-2 (CT). & $\mathrm{X}$ & & & & & & \\
\hline VIII-7 (CT) & $\mathrm{X}$ & & & & & & \\
\hline Vayeltaj 3 (CT) & $\mathrm{X}$ & & $\mathrm{X}$ & & Spondylus & & \\
\hline
\end{tabular}

CuAdro 3. Artefactos no cerámicos encontrados en los depósitos rituales del valle de Ocosingo.

(CT: Clásico Tardío, PCA: Posclásico Antiguo)

Se debe de antemano subrayar la relativa escasez de artefactos importados en ambos contextos. Ni un tercio de las 57 sepulturas y de los 33 depósitos rituales registrados en las cinco temporadas contienen otros objetos además de cerámica. ${ }^{24}$ De este total de 17 sepulturas y nueve depósitos excavados con ofrendas importadas, todos incluyen jadeíta o piedras verdes, principalmente pequeños objetos, cuentas, anillos o fragmentos, en cantidades bajas. Como vimos, y a falta de estudios geológicos y físicos, resulta difícil diferenciar las materias primas, y no podemos afirmar una procedencia de los yacimientos del Motagua o de los hipotéticos yacimientos de Chalchihuitán (ver nota 12). Por supuesto, al conjunto de esos artefactos podemos añadir algunos fragmentos encontrados en las excavaciones generales, en el sitio 75 (Rancho San José Solórzano) por ejemplo (Becquelin, Taladoire et al., 1990: 1606), y los objetos de la colección Squier conservados en el American Museum of Natural History (Easby, 1961). Este último conjunto reúne once piezas, algunas de un tamaño medio (más de $11 \mathrm{~cm}$ de largo).

Las últimas excavaciones dirigidas por Yadeun permitieron naturalmente el hallazgo de varias sepulturas y de depósitos rituales. De esos descubrimientos, sólo podemos documentar aquí el depósito excavado en la Estructura D5-2 (el Templo del Espejo Humeante, según la designación de este autor). Ayala Falcón (1995: 142,228 ) proporciona una lista detallada de los artefactos, que incluyen 40 nava-

\footnotetext{
${ }^{24}$ Por supuesto, varias sepulturas habían sido saqueadas, como la del Rancho Joaquín Millares (sitio 55), y se supone que las piezas de jade del American Museum of Natural History podrían proceder de la Sepultura IV-1.
} 
jas de obsidiana, un collar, varias hachas de jade (una de ellas con inscripciones) ${ }^{25}$ y otros objetos de piedra verde (piezas bifaciales y cinceles).

El total, incluyendo las piezas del American Museum of Natural History, no representa entonces una muestra importante, alrededor de 3 o $4 \mathrm{~kg} .{ }^{26}$ Sólo en la tumba de K'inich Janaab' Pakal, en Palenque, los objetos de jade recuperados alcanzan los $3.5 \mathrm{~kg}$ (Filloy Nadal, 2014: 242).

En su estudio de las esculturas, Baudez (Becquelin y Baudez 1979-82: 904) nota la escasez relativa de cuentas tubulares o de mantas con cuentas de jade, en el atavío de los dirigentes. Ayala Falcón (1995), por su lado, documenta el uso de orejeras en tejidos, en varias representaciones de dirigentes involucrados en rituales de sacrificio. Por supuesto, los reyes de Toniná están representados con casi todos los símbolos usuales del poder, joyas (orejeras, narigueras, pectorales), la barra ceremonial, cinturones gruesos y altos tocados muy elaborados. Pero muchos de esos ornamentos pueden ser confeccionados en otras materias primas, como madera, tejidos, pieles, conchas, plumas, piedras verdes. Los altos tocados de los gobernantes mayas estaban hechos de materiales perecederos ligeros decorados sólo con adornos en su cara visible (García Moreno, 2005). Por otro lado, las representaciones de dirigentes en Toniná, aunque impresionantes y de alta calidad, no constituyen la parte más importante del corpus escultórico, en comparación con las imágenes de cautivos o los monumentos con inscripciones glíficas (los discos y los pedestales, por ejemplo). Finalmente, no podemos descartar la posibilidad de representaciones codificadas de acuerdo con los cánones estéticos de la simbología maya, sin que esta riqueza iconográfica se traduzca en una presencia efectiva.

Eso sugiere de manera indirecta que el jade y la jadeíta escaseaban en Toniná, en comparación con otras entidades vecinas, Palenque (Filloy Nadal, 2014), Yaxchilán (García Moll, 2004) o Cancuén (Demarest et al., 2014) por ejemplo. ${ }^{27}$ Considerando el acceso fácil de Toniná a los hipotéticos yacimientos de Chalchihuitán, podemos suponer que parte de su abastecimiento en piedras verdes procedía de esa fuente, pero no se pueden descartar importaciones de los yacimientos del valle del Motagua, u otros métodos de adquisición, por tributo, saqueos o comercio. Todo indica que Toniná no disponía de una cantidad importante de piedras verdes.

La pirita no se encuentra en los alrededores de Toniná, pero es un mineral muy común en toda Mesoamérica. Resulta imposible definir una procedencia exacta.

${ }^{25}$ Se trata quizá del hacha ilustrada por Graham (2006: 128. Miscellaneous 6) en el museo de sitio.

${ }^{26}$ En el museo de sitio están expuestas diversas piezas de jade y de piedras verdes (cuentas, orejeras, pectorales), procedentes tanto de las excavaciones francesas como del proyecto mexicano. Eso significa un aumento de las cantidades registradas, pero no realmente significativo en términos globales.

${ }^{27}$ Cabe notar la relativa escasez de jade y de piedras verdes en Piedras Negras, donde sólo 12 de las 122 sepulturas contienen jade (Golden et al., 2012: 15). 
Además, como los objetos de pirita probablemente formaban parte de espejos (Becquelin y Baudez, 1979-82: 982-83; Pereira y Latsanopoulos, 2009), podemos suponer una importación como artefactos terminados. ${ }^{28}$

Como vimos, el ámbar se encuentra en varias zonas cercanas en los Altos de Chiapas, lo que supone una adquisición fácil. El granate también existe en varias partes de la república, y se documentaron yacimientos en Oaxaca y en el sur de Chiapas (Estrada Carmona et al., 2009). Una adquisición de cualquiera de ambas áreas resulta muy probable. El cristal de roca puede encontrarse en los Altos de Chiapas o de Guatemala.

Los dientes fósiles de tiburón provienen en cantidad notable de los depósitos geológicos de los alrededores de Palenque. Además de los ejemplares encontrados en sepulturas y depósitos rituales, se registró la presencia de varios individuos en otros contextos. A los dientes fósiles, debemos añadir espinas de rayas, dientes de tiburón blanco, así como un diente de cocodrilo (Álvarez, 1982; Álvarez, Ocaña y Valentín M., 1990). Todos esos fragmentos, tal vez utilizados en ritos sacrificiales, proceden de la costa del Golfo o de los alrededores de Palenque sin que podamos afirmar si fueron adquiridos por comercio, o como parte de tributo, después de las victorias de Toniná sobre su principal enemigo.

Una mención especial se debe dedicar al fragmento de coral de la Sepultura 6 de Laltic. Aunque raro, el coral ha sido encontrado en algunas ciudades como Uaxactún, Copán o Piedras Negras (Andrews, 1969; Becquelin, Taladoire et al., 1990: 1810). La procedencia más probable sería el Caribe, pero no se puede descartar el área de la costa del Golfo. Una adquisición desde Tabasco resulta entonces posible.

El oro, el cobre y los otros fragmentos metálicos proceden de los Altos de Guatemala. Los estudios de Grinberg y Franco (1982) confirman este origen y su similitud con los artefactos metálicos hallados en el cenote de Chichén Itzá. Además, se encontraron en Tenam Puente, fechados para el Posclásico Temprano, anillos y colgantes de cobre "similares a los reportados en Toniná y Chinkultic" que, según Jacinto y Aguilar (1996: 31 y 35), proceden también de las tierras altas guatemaltecas.

El conjunto de esos elementos exógenos tiene entonces las mismas procedencias que la mayoría de los artefactos documentados con anterioridad, es decir, los Altos de Guatemala y de Chiapas y las planicies tabasqueñas, el área ocupada por los zoques al noroeste de la entidad.

Se encontraron también en las excavaciones tres recipientes en tecali, dos en el grupo residencial F4, en la primera terraza de la acrópolis, excavado en la Operación III, y uno en la Sepultura IV-6. Esos artefactos constituyen obviamente adquisiciones foráneas, ya que los yacimientos documentados se ubican en Honduras o en la región del valle de Tehuacán, en el Altiplano mexicano (Testard, 2014: 725-726). Resulta imposible, por el momento, precisar la procedencia exac-

${ }^{28}$ La hematita podía utilizarse también. 
ta del tecali;, aunque, como el granate, podría ser adquirido desde el Altiplano por intercambio con los zoques.

Para finalizar, es necesario insistir sobre la abundancia relativa de conchas, entre ellas el Spondylus, ${ }^{29}$ a pesar de que, como dijimos, las diferentes especies de moluscos marinos sólo representan 2.2 \% del total (Valentín M. y Polaco, 1990). Los estudios faunísticos permitieron identificar muchas especies diferentes tanto del Pacífico como del Atlántico. Ayala Falcón (1995, citando a Valentín y Polaco, 1990) nota la predominancia de individuos procedentes de la costa del Golfo (139) sobre los del Pacífico (11). Obviamente, la gente de Toniná buscaba abastecerse de manera sistemática, sin que podamos definir sus modos de adquisición, aun si el comercio resulta más probable.

\section{Vestidos}

Este aspecto resulta difícil de documentar. La abundancia de fauna puede proporcionar numerosas pieles, en especial para los dignitarios. Como vimos, los ficus abundan, y el algodón (Gossypium barbadense L.) puede cultivarse en el valle (Puig y Usselmann, 1982, 1990), pero dudamos que la producción local sea suficiente para abastecer las necesidades de la población. Dos fragmentos de objetos en algodón fueron encontrados en la Sepultura IV-2 (Becquelin y Baudez, 1979-82: 1034). Las excavaciones proporcionaron un número muy reducido de malacates (38) y sólo algunas agujas de hueso, quizá de uso ritual en el autosacrificio. Todos los malacates provienen de excavaciones generales, principalmente del basurero de la Operación III (Grupo F4), el único contexto doméstico excavado de modo amplio y sistemático, dejando abierta la posibilidad que haya existido alguna actividad textil organizada.

\section{A manera de síntesis}

Para sintetizar, a pesar de la amplia distribución espacial de las excavaciones tanto intensivas como exploratorias, en Toniná y en el valle, las mismas no permitieron identificar ningún taller, y, muy probablemente, la inmensa mayoría de los artefactos resultaba de una producción local, a nivel doméstico, a partir de materias primas locales (arcilla, piedras, madera), lo que confirma de manera global la afirmación de Rodriguez-Loubet (1990: 1794) de una comunidad autárquica, aprovechando los recursos disponibles en las inmediaciones. Pero a la riqueza geológica, florística y faunística del valle responde una economía no sólo sencilla, sino casi pobre. Contrasta con esta actividad doméstica local la presencia, aunque en pocas cantidades, de productos importados (piedras verdes, metales, conchas

\footnotetext{
${ }^{29}$ Un número elevado de conchas de Spondylus está expuesto en el museo de sitio, lo que sugiere que las últimas excavaciones contribuyeron a aumentar la muestra.
} 
exóticas, pirita, esquisto, obsidiana), que se reunen principalmente en la ciudad de Toniná, muchas veces en contextos funerarios o rituales. Sólo se encontraron elementos de prestigio en las excavaciones de tres sitios menores, Santa Teresa (Clásico Temprano), Laltic y Vayeltaj, en los mismos contextos rituales (sepulturas). Esta repartición significa una concentración de las prestigiosas riquezas foráneas entre las élites de Toniná ${ }^{30}$ o de sitios secundarios donde residían los nobles (Taladoire, 2015). Eso sugiere una organización socio-política fuertemente jerarquizada, y métodos de adquisición de las materias primas muy diferentes, en conformidad con el estatus socio-político.

Resulta difícil definir los modos de adquisición de esos elementos exógenos, y podemos entonces suponer varias modalidades. La casi ausencia, en la inmensa mayoría de los sitios secundarios, de materias primas importadas implica que el grueso de la población no tenía acceso a esos productos, salvo, de modo ocasional, en sitios del Clásico Temprano como Santa Teresa, o en lugares donde vivían dirigentes menores (Laltic, Vayeltaj, Mosil) (Taladoire, 2015). Para las élites de Toniná, el comercio y los regalos pueden constituir la primera modalidad, conforme con las prácticas documentadas en numerosas ciudades mesoamericanas del intercambio de bienes de lujo entre miembros de las familias dirigentes. Como hemos visto, la producción doméstica permitía abastecer las necesidades básicas de la población, y nuestras excavaciones no identificaron ningún taller especializado, lo que no significa su ausencia. Ambas características minimizan la posibilidad de la presencia de mercados, tal como se ha propuesto para otras ciudades como Tikal o Chunchucmil (Masson y Freidel, 2012). Al contrario, la presencia, aunque reducida, de materias primas exógenas implica la existencia de una red de intercambios, y consecutivamente de posibles mercaderes. Toniná disponía, en su territorio, de varias riquezas como su cerámica, el ámbar, las plumas de quetzal, y quizá el pino para intercambiar por otros productos codiciados.

Entre las diferentes materias primas exógenas documentadas, hemos encontrado de manera sistemática dos fuentes de abastecimiento: los Altos de Chiapas y de Guatemala (piedras duras, metales, obsidiana) al oeste y al sureste de la entidad; y la región fronteriza entre la entidad y las tierras bajas de Tabasco (cerámicas finas, conchas, posiblemente cacao, hule) al noroeste.

Es en esta última región donde Toniná, y su aliado Sib'ikté, concentraron sus mayores esfuerzos bélicos, en especial contra Palenque, pero también contra Tortuguero (Taladoire, 2015). El control de la región de Tila hubiera abierto para Toniná un corredor comercial hacia las ricas planicies de Tabasco. En nuestra opinión, no es una casualidad si esas actividades bélicas oponen precisamente a Toniná con las ciudades de tradición cholana, mientras no tenemos evidencias de conflictos con las entidades socio-políticas de las tierras altas de Chiapas, ni con

\footnotetext{
${ }^{30}$ Los ornamentos descubiertos por el proyecto de Yadeun, actualmente expuestos en el museo de sitio, provienen en su casi totalidad de sus excavaciones en la ciudad, lo que confirma de manera indirecta la preeminencia de las élites locales en la adquisición de tales bienes de prestigio.
} 
las poblaciones zoques de Tabasco. Las escasas evidencias de intercambio entre la entidad de Toniná y la región ocupada por los zoques (las cerámicas Anaranjado fino, el ámbar, los dientes de tiburón, tal vez el tecali) atestiguan relaciones continuas, que además persistían después de la caída de la ciudad a principios de la fase Chenek, un momento en el cual los habitantes del valle con seguridad ya no disponían de fuerzas suficientes para proseguir sus actividades bélicas.

No podemos tampoco descartar otras modalidades de adquisición, como los saqueos de ciudades conquistadas, lo que ocurrió en Palenque en 711 d.C., y los tributos que pagaban ellas, por ser vencidas o para rescatar a sus dirigentes (McAnany, 2010: 270-78). El saqueo permite la obtención inmediata de piezas valiosas (tal vez las cerámicas Chablekal), pero no de grandes cantidades de objetos, pues el ejercito victorioso no puede cargar, de regreso, bultos voluminosos. Por supuesto, los prisioneros y los cautivos constituyen un tipo de recurso adicional específico, indispensable para el prestigio de los dirigentes y para los rituales sacrificatorios. ${ }^{31}$ La abundancia de representaciones de cautivos en el arte de Toniná confirma la importancia de este recurso humano, de corta duración (Becquelin y Baudez, 1979-82). Debemos notar que varios cautivos, como K'an Joy Chitam II de Palenque (M. 122), están representados con sus joyas (collar, orejeras) puestas, aun si han sido privados de su atavío y están atados con cuerdas (Martin y Grube, 2000: 183).

Al contrario, los tributos proporcionan cantidades superiores de materias primas o de artefactos ya fabricados, y constituyen una fuente de abastecimiento relativamente continua, por lo menos durante varios años, hasta el próximo conflicto.

\section{Conclusiones}

De acuerdo con los datos disponibles, y sin prejuzgar las posibles aportaciones de las últimas excavaciones, podemos entonces sintetizar el conjunto de bases económicas de la entidad de Toniná. La población relativamente reducida del valle de Ocosingo disponía en grandes cantidades de los recursos necesarios para su vida cotidiana y sus actividades básicas, como la construcción y el mantenimiento de los templos y otros edificios de la ciudad. Como lo notaron Becquelin (Becquelin y Baudez, 1979-82) y Rodriguez-Loubet (1990), para la alfarería y la lítica, se aprovecharon de modo sistemático los recursos locales para las actividades artesanales, probablemente en el contexto de una producción doméstica. En esta perspectiva, la población local no se diferencia demasiado de la mayoría de las otras entidades políticas mayas de las tierras bajas. Como escribe Demarest (et al., 2014: 189): "Most Classic period Maya state economies appear to have

\footnotetext{
${ }^{31}$ Podemos también suponer que los bienes de los prisioneros (joyas, armas) eran confiscados por los vencederos, mientras algunos de los cautivos podían servir de cargadores durante el regreso de la expedición victoriosa.
} 
been largely sustained in their basic subsistence necessities within a more limited region”. En el caso de Toniná, esta región parece limitarse al valle de Ocosingo.

De manera simultánea, las élites buscaban acceder a bienes de prestigio (el jade y las piedras verdes, los espejos de pirita, las plumas de quetzal), a bienes importados (la obsidiana, el basalto, el esquisto) o a artefactos rituales importantes (los instrumentos de autosacrificio), ausentes en su territorio. A este efecto, sólo les quedaban dos posibilidades: el comercio y el control territorial de fuentes de abastecimiento. Considerando las relaciones bélicas de Toniná con la mayoría de las ciudades circundantes de las tierras bajas mayas, resulta poco probable la existencia de redes de intercambio. La actitud agresiva de Toniná hacía las ciudades de la cuenca del Usumacinta (Bonampak, Sak T’zi) tal vez se justifica por la búsqueda de un acceso a los abundantes recursos de jade que circulaban desde Cancuén hacia las otras ciudades río abajo (Yaxchilán, Piedras Negras, Palenque), por el eje del valle del Usumacinta (Demarest et al., 2014). ${ }^{32}$ Obviamente, las victorias de Toniná sobre sus enemigos podían contribuir, por medio de los tributos o de los rescates de prisioneros de alto rango, a la obtención ocasional de productos codiciados, pero de ninguna manera con flujos regulares. Resulta significativa, al respecto, la relativa escasez de bienes de prestigio de las tierras bajas centrales, $\mathrm{y}$, al contrario, la presencia de cantidades significativas de productos obtenidos de áreas con las cuales Toniná tenía relaciones seguidas. De las tierras altas de Chiapas y de Guatemala provienen la obsidiana, las piedras verdes, la pirita, el basalto, los objetos metálicos, los recipientes plomizos. De la frontera norte, colindando con el territorio zoque y las planicies de Tabasco, proceden los recipientes del grupo Anaranjado Fino, los dientes de tiburón y de cocodrilo, el ámbar, el cacao, el hule, las plumas de quetzal, tal vez los vasos de tecali.

Obviamente, Toniná, a diferencia de su actitud agresiva en contra de numerosas ciudades mayas vecinas de las tierras bajas, mantenía relaciones económicas no sólo continuas, sino amigables, tanto con las comunidades de los Altos de Chiapas y tal vez de los Altos de Guatemala, como con las poblaciones zoques de las planicies de Tabasco. En este último caso, quizá el mantenimiento de rutas de abastecimiento sería una de las razones de los conflictos entre las entidades de Palenque y de Toniná. Pero sólo la publicación de más datos de la cultura material de las últimas excavaciones podría confirmar o negar las hipótesis aquí expuestas.

\section{Agradecimientos}

Quisiera primero agradecer a Pierre Becquelin, director del proyecto durante las cinco temporadas, su apoyo permanente en esta tentativa de reinterpretación

\footnotetext{
32 Se necesita recordar que la cuenca del Usumacinta no constituía una ruta comercial sencilla, debido a los conflictos entre distintas entidades y al caracter aleatorio de la navegación en ciertos tramos (Golden et al., 2012).
} 
de los datos. Como siempre, Rosario Acosta revisó cuidadosamente este texto, corrigió mi español y sugirió diversos cambios y aclaraciones; quedo más que agradecido con su dedicación permanente. Chloé Andrieu leyó este ensayo, y me proporcionó numerosas observaciones pertinentes, en especial respecto a la obsidiana, así como la documentación bibliográfica correspondiente; le agradezco sus comentarios, que enriquecieron mis hipótesis, hasta si a veces las contradicen: eso es la base misma de la investigación científica. Charlotte Arnauld, responsable de las excavaciones del Grupo F4, básico para la comprensión de la historia de Toniná y la definición de su trayectoria cronológica, propuso varias correcciones y proporcionó algunas referencias suplementarias; le agradezco su valiosa ayuda.

\section{BIBLIOGRAFÍA}

Álvarez, Ticul

1982 "Análisis del material zoológico de las excavaciones en Toniná, Chiapas", Toniná, une cité maya du Chiapas, pp. 1127-1142, Pierre Becquelin y Claude François Baudez (eds.). Paris: Misión Arqueológica y Etnológica Francesa en México y Association pour la Diffusion de la Pensée Française (Collection Etudes Mésoaméricaines, I [6], 2).

Álvarez, Ticul, Aurelio Ocaña y Norma Valentín M.

1990 "Identificación de los restos óseos procedentes de las excavaciones de Toniná”, Toniná, une cité maya du Chiapas, pp. 1831-1845, Pierre Becquelin y Eric Taladoire (eds.). México: Centro de Estudios Mexicanos y Centro-Americanos (Collection Etudes Mésoaméricaines, I [6], 4).

Andrews, Edward Wyllys IV

1969 The Archaeological Distribution and Use of Mollusca in the Maya Lowlands. New Orleans: Tulane University (Middle American Research Institute. Publication 34).

Andrieu, Chloé, Christophe Helmke, Harri Kettunen, Eric Taladoire y Robert Tamba

2012 "New Maya Paintings at Bolonkin, Chiapas", Mexicon, XXXIV (1): 7-10.

Arnauld, Marie-Charlotte

1990a "Opération III: nouvelles fouilles dans le groupe F4", Toniná, une cité maya du Chiapas, pp. 1505-1529, P. Becquelin y Eric Taladoire (eds.). México: Centro de Estudios Mexicanos y Centro-Americanos (Collection Etudes Mésoaméricaines, I [6], 4).

1990b "El comercio clásico de obsidiana: rutas entre tierras bajas y tierras altas en el área maya”, Latin American Antiquity, 1 (4): 347-367.

Ayala Falcón, Maricela

1995 "The History of Toniná through its Inscriptions", tesis de doctorado en Filosofía. Austin: The University of Texas at Austin. 
1997 "Who Were the People of Toniná?", The Language of Maya Hieroglyphs, pp. 69-75, Martha Macri y Anabel Ford (eds.). San Francisco: Precolumbian Art Research Institute.

Bassie-Sweet, Karen (ed.)

2015 The Ch'ol Maya of Chiapas. Norman: University of Oklahoma Press.

Becquelin, Pierre y Claude F. Baudez (eds.)

1979-82 Toniná, une cité maya du Chiapas. Paris: Misión Arqueológica y Etnológica Francesa en México y Association pour la Diffusion de la Pensée Française (Collection Etudes Mésoaméricaines I [6], 1. Misión Arqueológica y Etnológica Francesa en México, I [6], 2-3.).

Becquelin, Pierre, Dominique Michelet y Eric Taladoire

1994 "Prospection de contrôle dans la vallée d'Ocosingo, Chiapas, Mexique", Journal de la Société des Américanistes, 80: 185-190.

Becquelin, Pierre y Eric Taladoire (eds.)

1990 Toniná, une cité maya du Chiapas. México: Centro de Estudios Mexicanos y Centro-Americanos (Collection Etudes Mésoaméricaines, I [6], 4).

Bishop, Ronald, Erin Sears y M. James Blackman

2005 "A través del Río de Cambio", Estudios de Cultura Maya, XXVI: 17-40.

Blom, Frans y Oliver LaFarge

1927 Tribes and temples. A record of the expedition to Middle America conducted by the Tulane University of Louisiana in 1925. New Orleans: Tulane University (Middle American Research Series, Publication 1).

Caso, Alfonso

1969 El tesoro de Monte Albán. México: Instituto Nacional de Antropología e Historia y Secretaría de Educación Pública.

Clark, John Edward

1986 "From Mountains to Molehills: A Critical Review of Teotihuacan's Obsidian Industry", Research in Economic Anthropology. Supplement 2: Economic Aspects of Prehispanic Highland Mexico, pp. 23-74, B. Isaac (ed.). Greenwich-London: JAI Press.

Coe, Michael Douglas

1973 The Maya Scribe and his World. New York: The Grolier Club.

Cruz Romero, José Luis

2012 "Los yugos y hachas votivas de Palenque”, Arqueología Mexicana, 113: 52-54.

Culbert, Patrick Thomas

1965 The Ceramic History of the Central Highlands of Chiapas, Mexico. Provo, Utah: Brigham Young University (New World Archaeological Foundation Publication 14, paper 19). 
Demarest, Arthur

2014 "Economy, Exchange and Power: New Evidence from the Late Classic Maya Port City of Cancuén”, Ancient Mesoamerica, 25: 187-219.

Demarest, Arthur Andrew, Prudence Rice y Don Rice (eds.)

2004 The Terminal Classic in the Maya Lowlands: Collapse, Transition and Transformation. Boulder: University of Colorado Press.

Easby, Elizabeth

1961 "The Squier Jades from Toniná, Chiapas", Essays in pre-Columbian Art and Archaeology, pp. 60-80, Samuel Kirkland Lothrop et al. (eds.). Cambridge: Harvard University Press.

Ekholm-Miller, Susanna

1973 The Olmec Rock-carving at Xoc, Chiapas, Mexico. Provo, Utah: Brigham Young University (New World Archaeological Foundation Papers, 32).

Estrada Carmona, Juliana, Bodo Weber, Lutz Hecht y Uwe Martens

2009 "Trayectoria P-T-t de rocas metamórficas de la unidad Custepec en el Macizo de Chiapas central, Chiapas, México", Revista Mexicana de Ciencias Geologicas, 26 (1): 243-259, <http://www.scielo.org.mx/pdf/rmcg/v26n1/v26n1a19.pdf>.

Filloy Nadal, Laura

2014 Costume et insignes d'un roi maya de Palenque, Chiapas, Mexique. K'inich Janaab' Pakal de Palenque. Oxford: Archaeopress (Paris Monographs in American Archaeology, 34/BAR International Series, 2590).

Forné, Mélanie Chloé Andrieu y Arthur Andrew Demarest

2014 "Las actividades económicas como parte de una estrategia política: el caso de Cancuén, una ciudad entre Tierras Altas y Tierras Bajas en el Clásico Tardío", Socio-Political Strategies among the Maya from the Classic Period to the Present, pp. 33-50, V. A. Vásquez López, R. Valencia Rivera y E. Gutiérrez González (eds.). Oxford: Archaeopress (BAR International Series, 2619).

Forné Mélanie, Silvia Alvarado y Paola Torres

2011 "Cronología cerámica en Cancuén: historia de una ciudad del Clásico Tardío”, Estudios de Cultura Maya, XXXVIII: 11-40.

García Moll, Roberto

2004 "Shield Jaguar and Structure 23 at Yaxchilán”, Courtly Art of the Ancient Maya, pp. 268-70, M. Miller y S. Martin (eds.). New York: Thames and Hudson.

García Moreno, Renata

2005 "Les sépultures royales de Calakmul, Mexique: technologie, iconographie et symbolisme. L'apport de la conservation et l'étude physico-chimique du mobilier en support périssable", tesis de doctorado. Paris: l'Université de Paris 1, Panthéon-Sorbonne. 
Golden, Charles y Andrew Scherer

2013 "Territory, Trust, Growth and Collapse in Classic Period Maya Kingdoms", Current Anthropology, 54 (4): 397-435.

Golden, Charles, Andrew Scherer, René Muñoz y Zachary Hruby

2012 "Polities, Boundaries and Trade in the Classic Period Usumacinta River Basin”, Mexicon, XXXIV (1): 11-19.

Graham, Ian

2006 Corpus of Maya Hieroglyphic Inscriptions, vol. 9, part 2: Toniná. Cambridge, Mass.: Peabody Museum of Archaeology and Etnology, Harvard University.

Grinberg, Dora M. K. de y Francisca Franco Velásquez

1982 "Estudio químico y metalúrgico de los objetos de metal de Toniná, Chiapas", Toniná, une cité maya du Chiapas, pp. 1143-1164, Pierre Becquelin y Claude François Baudez (eds.). Paris: Misión Arqueológica y Etnológica Francesa en México y Association pour la Diffusion de la Pensée Française 8 (Collection Etudes Mésoaméricaines, I [6], 2).

Guillemin, Jorge

1968 “Un ‘yugo' de madera para el juego de pelota”, Antropología e Historia de Guatemala, XX (1): 25-33.

Jiménez Alvarez, Socorro, Alan Enrique Méndez Cab, Charles Golden y Andrew Scherer

2014 "La cerámica del período Clásico Tardío procedente de la región entre los ríos Chocoljá y Busiljá, en el río Usumacinta medio de Chiapas", Los investigadores de la Cultura Maya, 22, tomo II, pp. 181-199. México: Universidad Nacional Autónoma de Campeche.

Kurosaki Maekawa, Mitsuru

2006 "Estudio sobre los yugos", tesis de Licenciatura en Arqueología. México: Escuela Nacional de Antropología e Historia.

Laló Jacinto Gabriel y Luz María Aguilar

1996 "El Posclásico Temprano en Tenam Puente", Quinto Foro de Arqueología de Chiapas, pp. 23-37. Tuxtla Gutiérrez: Gobierno del Estado de Chiapas y Universidad de Ciencias y Artes del Estado de Chiapas.

Liendo Stuardo, Rodrigo (coord.)

2011 B’aakal. Arqueología de la región de Palenque, Chiapas, México. Temporadas 19962006. Oxford: Archaeopress (Paris Monographs in American Archaeology, 26/ BAR International Series, 2203).

López Luján, Leonardo, Jaime Torres y Aurora Montúfar

2003 "Los materiales constructivos del Templo Mayor de Tenochtitlan", Estudios de Cultura Náhuatl, 34: 137-166.

López Varela, Sandra Lorena

1989 Análisis y clasificación de la cerámica de un sitio maya del Clásico: Yaxchilán, México. Oxford: Archaeopress (BAR International Series, 535). 
Lowe, Lynneth Susan

2001 "Evidencias arqueológicas del ámbar en el área maya: usos y distribución", XIV Simposio de Investigaciones Arqueológicas en Guatemala 2000, pp. 772-785, Juan Pedro Laporte, Ana Claudia de Suasnávar y Barbara Arroyo (eds.). Guatemala: Museo Nacional de Arqueología y Etnología.

2004 El ámbar de Chiapas y su distribución en Mesoamérica. México: Universidad Nacional Autónoma de México, Instituto de Investigaciones Filológicas, Centro de Estudios Mayas (Cuadernos del Centro de Estudios Mayas, 31).

Manzanilla, Linda (ed.)

1986 Unidades habitacionales mesoamericanas y sus áreas de actividad. México: Universidad Nacional Autónoma de México.

1993 Anatomía de un conjunto residencial teotihuacano en Oztoyahualco. México: Universidad Nacional Autónoma de México, Instituto de Investigaciones Antropológicas, 2 vols.

Martin, Simon y Nikolai Grube

2000 Chronicle of the Maya Kings and Queens. Deciphering the Dynasties of the Ancient Maya. London: Thames and Hudson.

Masson, Marilyn y David Freidel (eds.)

2002 Ancient Maya Political Economies. New York y Oxford: Altamira Press.

2012 "An Argument for Classic Era Maya Market Exchange", Journal of Anthropological Archaeology, 31 (4): 455-484.

Mateos González, Frida Itzel

1996 “Toniná. Un recorrido por los relieves”, Eighth Palenque Round Table 1993, pp. 143-152, Merle Greene Robertson, Martha Macri y Jan MacHargue (eds.). San Francisco: Precolumbian Art Research Institute.

1997 Toniná, la pintura mural y los relieves: técnica de manufactura. México: Instituto Nacional de Antropología e Historia y Universidad Nacional Autónoma de México, Centro de Investigaciones Humanísticas de Mesoamérica y del Estado de Chiapas (Colección Científica, 358).

McAnany, Patricia Ann

1993 "Resources, Specialization and Exchange in the Maya Lowlands", The American Southwest and Mesoamerica. Interdisciplinary Contributions to Archaeology, pp. 213-245, Jonathon Ericson y Timothy Baugh (eds.). New York: Plenum Press.

2010 Ancestral Maya Economies in Archaeological Perspective. Cambridge: Cambridge University Press.

Muñoz, Arturo René

2006 La secuencia cerámica de Piedras Negras, Guatemala: tipos y variedades, FAMSI, <www.famsi.org/reports/02055es/>.

Navarrete, Carlos

1973 "El sistema prehispánico de comunicaciones entre Chiapas y Tabasco", Anales de Antropología, X: 33-92. 
Paris, Elizabeth H., Eric Taladoire y Thomas Arvol Lee Whiting

2013 "Estatus, poder y arquitectura del paisaje en el Centro Monumental de Moxviquil, Chiapas, México", Anuario del Centro de Estudios Superiores de México y Centroamérica 2011, pp. 13-48, Víctor Manuel Esponda Jimeno (ed.). Tuxtla Gutiérrez: Universidad de Ciencias y Artes de Chiapas.

2015 "Return to Moxviquil: New Investigations and Old Collections", Ancient Mesoamerica, 26 (1): 81-112.

Pereira, Grégory y Nicolas Latsanopoulos

2009 "Los reflejos del poder, una perspectiva comparativa acerca de los espejos de pirita teotihuacanos", ponencia presentada al coloquio Rituels et Pouvoir à Teotihuacan. Paris: Musée du quai Branly.

Puig, Henri y Pierre Usselmannn

1982 "Une introduction au milieu physique de la vallée d'Ocosingo (Chiapas, Mexique): géomorphologie et végétation”, Cahiers des Amériques Latines, 25: 11-30.

1990 "Une introduction au milieu physique de la vallée d'Ocosingo (Chiapas, Mexique): géomorphologie et végétation”, Toniná, une cité maya du Chiapas, pp. 1491-1501, Pierre Becquelin y Eric Taladoire (eds.). México: Centro de Estudios Mexicanos y Centro-Americanos (Collection Etudes Mésoaméricaines, I [6], 4).

Rands, Robert, Ronald Bishop y Jeremy Sabloff

1982 "Maya Fine Paste Ceramics: an Archaeological Perspective", Excavations at Seibal, Department of Petén, Guatemala. Analysis of Fine Paste Ceramics, pp. 315343, Jeremy Sabloff (ed.). Cambridge: Harvard University (Memoirs of the Peabody Museum of Archaeology and Ethnology, vol. 15, $\mathrm{n}^{\circ} 2$ ).

Rodriguez-Loubet, François

1990 "Le matériel lithique", Toniná, une cité maya du Chiapas, pp. 1749-1804. Pierre Becquelin y Eric Taladoire (eds.). México: Centro de Estudios Mexicanos y Centro-Americanos (Collection Etudes Mésoaméricaines, I [6], 4).

Roose, Ninon

2006 "Le complexe des Hachas, Jougs et Palmes en Méso-Amérique", tesis de doctorado. Paris: Université de Paris 1, Panthéon-Sorbonne.

Sheseña Hernández, Alejandro y Alejandro Tovalín-Ahumada

2014 "Los sitios arqueológicos de Chilón, Náchoj, Mukana y Nátentsun, municipio de Chilón, Chiapas”, LiminaR, 12 (1): 53-64, <liminar.cesmeca.mx/index.php/ r1article/view/324>.

Sheseña, Alejandro y Thomas Arvol Lee Whiting

2004 "Yugo incrustado con glifos mayas procedente de los alrededores de Chilón, Chiapas", Mexicon, XXVI (6): 127-132.

Stephens, John Lloyd y Frederick Catherwood

1969 Incidents of Travel in Central America, Chiapas and Yucatán. New York: Dover Publications, Inc. 
Taladoire, Eric

2008 "El territorio y patrón de asentamiento de Toniná, Chiapas", ponencia presentada en la VI Mesa Redonda de Palenque. México: Instituto Nacional de Antropología e Historia

2015 “Towards a Reevaluation of the Toniná Polity”, Estudios de Cultura Maya, XLVI: 45-70.

Testard, Juliette

2014 "Pouvoir et altérité. Interactions suprarégionales à l'Epiclassique (600 à 900 apr. J.-C.) dans le Mexique central (Puebla-Tlaxcala et Morelos)", tesis de doctorado. Paris: Université de Paris 1, Panthéon-Sorbonne.

Valentín Maldonado, Norma y Oscar Polaco

1990 "Identificación de los moluscos procedentes de las excavaciones de Toniná", Toniná, une cité maya du Chiapas, pp. 1846-1851, Pierre Becquelin y Eric Taladoire (eds.). México: Centro de Estudios Mexicanos y Centro-Americanos (Collection Etudes Mésoaméricaines, I [6], 4).

Webster, David

2005 "Political Ecology, Political Economy and the Culture History of Resource Management at Copán”, Copán: The History of an Ancient Maya Kingdom, pp. 33-72, Edward Wyllys Andrews y William Fash (eds.). Santa Fe: School of American Research Press, Oxford.

Wichmann, Soren y Alfonso Lacadena

2005 "The Dynamics of Language in the Western Lowland Maya Region", Art for Archaeology's Sake. Material Culture and Style across the Disciplines, 33rd Annual Chacmool Conference, pp. 32-48, Andrea Waters-Rist, Christine Cluney, Calla McNamee y Larry Steinbrenner (eds.). Calgary, Canada: The Archaeological Association of the University of Calgary.

Yadeun Ángulo, Juan

1992 Toniná. El laberinto del inframundo. México: Espejo de Obsidiana y Gobierno del Estado de Chiapas.

1993 Toniná. México y Madrid: El Equilibrista y Turner Libros.

2001 "El museo de sitio de Toniná. Territorio del tiempo", Arqueología Mexicana, 50: 44-49.

2011 "K'inich Baak Nal chaak (Resplandeciente Señor de la Lluvia y el Inframundo) (652-707 d.C.). Toniná (Popo), Chiapas”, Arqueología Mexicana, 110: 52-57. 